Available online at https://jurnal.stmikroyal.ac.id/index.php/jurdimas

\title{
PENGARUH PEMBELAJARAN CTPS TERHADAP PERILAKU SISWA SDN 154 DESA TELUK JAMBU MUARO JAMBI
}

\author{
Lia Anggresani ${ }^{1 *}$, Randi Setiawan ${ }^{1}$ \\ ${ }^{1}$ Program Studi Farmasi, STIKes Harapan Ibu Jambi \\ email: anggresani@yahoo.com
}

\begin{abstract}
Diarrhea is the fifth largest disease that causes death. This disease usually caused by an unhealthy and clean lifestyle. The need to grow and develop a healthy life from childhood. Clean and healthy behavior (PHBS) can be started by washing hands using soap. In Teluk Jambu Village, the high diarrheal disease makes this community service activity carried out at SD Negeri 154 where the target of these activities is children. Washing your hands with soap is a way to kill germs that cause disease. The method used to make students easy to remember and apply must require appropriate media, for example, music which is then accompanied by a seven-step demonstration of hand washing, so that student's behavior changes are achieved after learning about how to wash hands using soal.
\end{abstract}

Keywords: behavior; CTPS (Handwashing With Soap); learning

\begin{abstract}
Abstrak: Diare merupakan penyakit terbesar kelima yang menyebabkan kematian. Penyakit ini biasanya disebabkan karena pola hidup yang tidak sehat dan bersih. Perlunya menumbuh kembangkan hidup sehat dari kecil. Perilaku Hidup Bersih dan Sehat (PHBS) bisa dimulai dari mencuci tangan dengan menggunakan sabun. Di desa Teluk Jambu tingginya penyakit diare membuat kegiatan pengabdian masyarakat ini dilaksanakan di SD Negeri 154 yang mana sasaran pengabdian ini adalah untuk anak-anak. Mencuci tangan dengan menggunakan sabun merupakan cara membunuh kuman penyebab penyakit. Metode yang digunakan agar siswa/i mudah mengingat dan mengaplikasikannya harus membutuhkan media yang tepat, misalnya musik yang kemudian diiringi dengan demonstrasi gerakan tujuh langkah cuci tangan, agar tercapainya perubahan perilaku siswa/i setelah diberikan pembelajaran mengenai cara mencuci tangan menggunakan sabun.
\end{abstract}

Kata kunci: CTPS (Cuci Tangan Pakai Sabun); pembelajaran; perilaku

\section{PENDAHULUAN}

Pendidikan dasar merupakan bekal bagi seseorang untuk dapat hidup bermasyarakat dimanapun di dunia ini. Pendidikan dasar dimulai dari taman kanak-kanak dan Sekolah Dasar. Sekolah merupakan tempat untuk belajar menulis, belajar membaca serta merupakan tempat kedua mereka untuk menumbukan kepribadian mereka dan juga dapat dijadikan sebagai media promosi kesehatan bagi anak-anak (Simatupang \& Simatupang, 2019). Pentingnya pendidikan kesehatan di Sekolah adalah untuk mencegah terjangkitnya penyakit pada anak-anak. Usia anak-anak sangat rentan terhadap berbagai penyakit seperti diare, batuk dan flu (Bangun, 2020).Diare menyebabkan kematian anak dibawah 3 tahun akibat sanitasi yang buruk sehingga menyebabkan kerugian ekonomi dari Produk Domestik Bruto sebesar 2,3\% (RI, 2009) dan menduduki urutan kelima penyakit yg menyebabkan kematian (Utami, 2018).

Diare merupakan keluarnya feses sebanyak 3 kali atau lebih selama satu hari 
Available online at https://jurnal.stmikroyal.ac.id/index.php/jurdimas

feses yg keluar dalam bentuk cair (Lailatul Mafazah, 2013). Gejala dari diare ini adalah demam, mata cekung, mual dan muntah, pucat, dehidrasi, lemah serta menurunkan pengeluaran urin (Al-Gallas, 2007; Chang, 2008). Diare dapat disebabkan oleh lemahnya kekebalan aktif pada bayi, makanan yang terkontaminasi bakteri tinja atau kontak secara langsung dengan tinja binatang atau manusia pada saat bayi hingga mulai merangkak (IDAI, 2012).

Adapun upaya yang bisa dilakukan untuk menciptakan kondisi bagi keluarga, individu ataupun masyarakat dengan membuka jalur komunikasi serta memberikan edukasi dan indormasi dalam menerapkan cara hidup sehat yaitu dengan Perilaku Hidup Bersih dan Sehat (Umaroh, 2016). Mencuci tangan memakai sabun sebelum dan sesudah melakukan kegiatan merupakan bagian dari Perilaku Hidup Bersih dan Sehat (PHBS). World Health Organization telah menetapkan cara-cara mencuci tangan pakai sabun (Organization, 2009) sehingga akan membunuh kuman penyebab penyakit. (Andriansyah \& Rahmantari, 2013).

Perilaku Hidup bersih dan sehat (PHBS) harus senantiasa diciptakan oleh semua lapisan masyarakat agar lingkungan menjadi sehat dan bersih (Andriansyah \& Rahmantari, 2013). Pola pikir hidup sehat sebaiknya ditanamkan sejak dini. Selain menggunakan sabun untuk mencuci tangan kita bisa juga menggunakan cairan antiseptik (hand sanitizer).

Penelitian yang dilakukan oleh (Desiyanto \& Djannah, 2013) terlihat bahwa mencuci tangan dengan hand sanitizer lebih efektif membunuh kuman dimana mereka menggunakan alkohol $60 \%$ pada hand sanitizer ini. Adanya penambahan alkohol pada antiseptik terkadang bisa membuat iritasi pada pemakainya jika tidak cocok dengan kondisi tangan si pemakai. Sedangkan penelitian yang dilakukan oleh (Cordita, 2017) menyatakan jumlah penurunan angka kuman lebih besar jika menggunakan sabun antiseptik dibandingkan dengan menggunakan hand sanitizer. Sehingga kami mengajarkan pola hidup sehat dengan cara mencuci tangan dengan menggunakan sabun.

Berdasarkan data yang didapatkan dari Bidan desa bahwa Diare merupakan penyakit terbesar di desa ini. Hal ini jugalah yang melatarbelakangi kami untuk melakukan pengabdian kepada anak-anak Sekolah Dasar di desa Teluk Jambu Kecamatan Taman Rajo kabupaten Muaro Jambi provinsi Jambi sehingga mereka lebih mengerti akan pentingnya hidup sehat. $\mathrm{Ku}-$ rangnya ilmu pengetahuan dan informasi yang menyebabkan tingginya kasus Diare di Desa Teluk Jambu.

Berdasarkan masalah yang timbul inilah, kami melakukan pengabdian masyarakat terutama kepada siswa/i SD Negeri 154 Desa Teluk Jambu Kecamatan Taman Rajo Kabupaten Muaro Jambi Provinsi Jambi dalam memberikan edukasi tentang Cara Mencuci Tangan Pakai Sabun sehingga terciptanya budaya bersih dan sehat.

\section{METODE}

Kegiatan ini dilaksanakan di SD Negeri 154 desa Teluk Jambu Kecamatan Taman Rajo kabupaten Muaro Jambi provinsi Jambi. Waktu pelaksanaan dilakukan pada hari Rabu, 12 Februari 2020, dengan sasaran penyuluhan yang ditargetkan pada siswa/i kelas I s/d VI.

Metode yang digunakan agar siswa/i mudah mengingat dan mengaplikasikannya harus membutuhkan media yang tepat, misalnya musik yang kemudian diiringi dengan demonstrasi gerakan tujuh langkah cuci tangan.

Langkah mencuci tangan yang benar menurut WHO adalah (Organization, 2009) :

1. a) Membasuh tangan dengan air

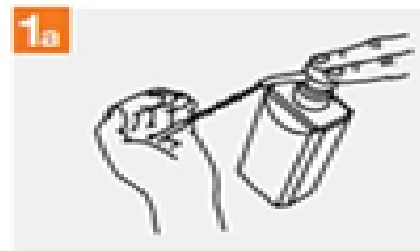


Available online at https://jurnal.stmikroyal.ac.id/index.php/jurdimas

b) Ambil sabun letakkan pada telapak tangan.

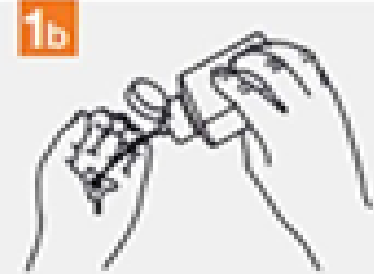

2. Gosokkan sabun dengan menggunakan kedua telapak tangan
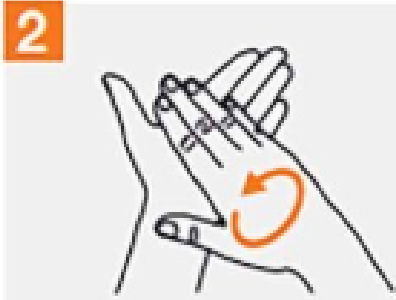

3. Telapak tangan kanan diletakkan di atas punggung tangan kiri dan sebalinya diulangi

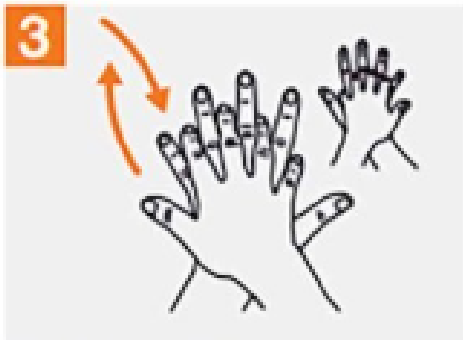

4. Telapak tangan kanan diletakkan ke telapak tangan kiri dengan jari saling terkait.

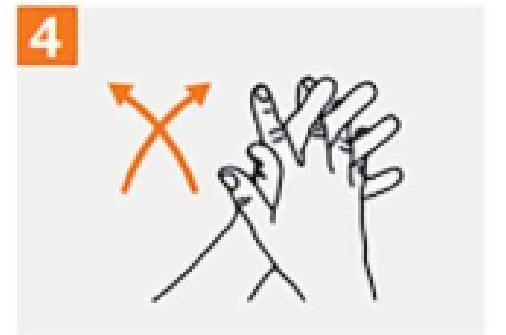

5. Tangan kiri dan kanan menggenggam satu sama lain dan jari bertautan agar sabun mengenai pangkal jari dan kuku.

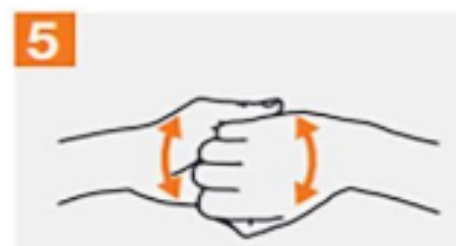

6. Ibu jari kiri digosok dengan tangan kanan begitupula sebaliknya.

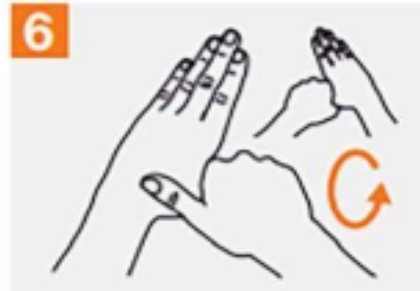

7. Jari-jari tangan kanan yang tergenggam di gosok di telapak tangan kiri dan begitupula sebaliknya.

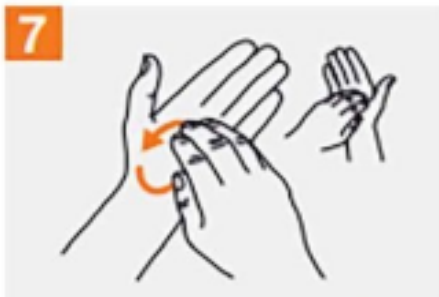

8. Keringkan tangan

\section{8}
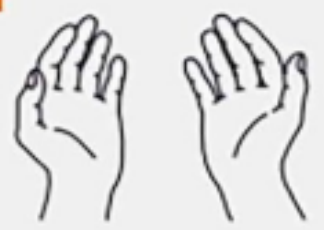

\section{PEMBAHASAN}

Pada penelitian ini, intervensi yang diberikan pada siswa/i SD Negeri 154 Desa Teluk Jambu berupa penyuluhan tentang cara mencuci tangan dengan menggunakan sabun melalui tahap adaptasi, inovasi dan mandiri yang membahas penyuluhan tentang mencuci tangan dengan menggunakan sabun, lagu cuci tangan, permainan dan praktek langsung mencuci tangan oleh siswa/i. 
Available online at https://jurnal.stmikroyal.ac.id/index.php/jurdimas

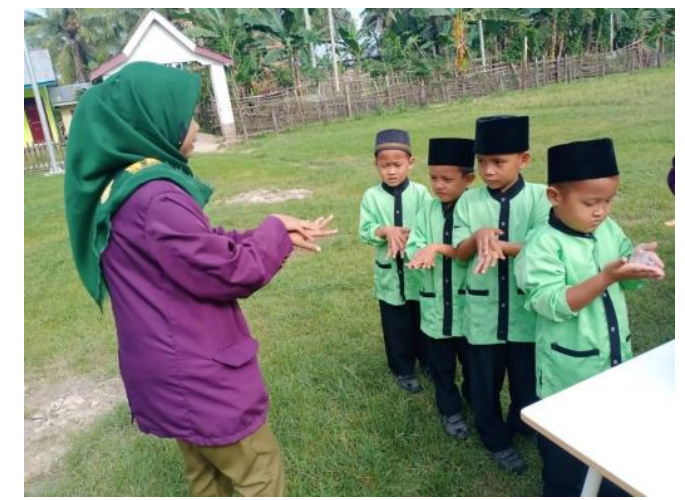

Gambar 1. Siswa/i SDN 154 Desa Teluk Jambu

Pemberian intervensi pada tahap adaptasi berupa penyuluhan dan pemberian pengetahuan tentang pengertian CTPS, langkah-langkah CTPS, dan praktik CTPS. Pada tahap adaptasi responden memperlihatkan pengetahuan setelah diberikan intervensi dibandingkan dengan sebelum diberikan intervensi.

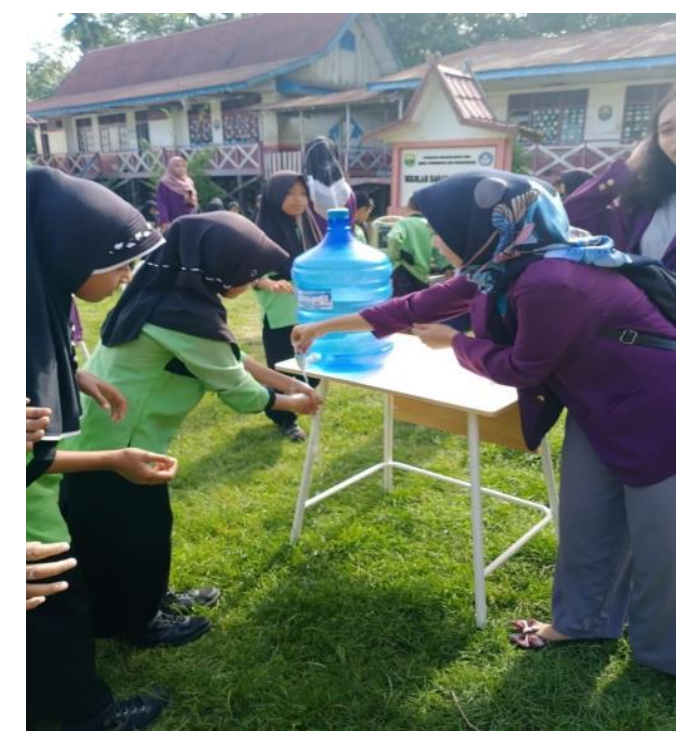

Gambar 2. Pemberian Intervensi CTPS

Siswa/i SD Negeri 154 menunjukkan reaksi yang positif dan sangat bersemangat pada saat diberikan materi ataupun sewaktu sesi praktik berlangsung. Inovasi penyampaian materi yang berbeda dan praktik yang mudah diingat diharapkan dapat mendorong keinginan siswa/i SD Negeri 154 Desa Teluk Jambu menerapkan dalam kehidupan sehari - hari sehingga bisa terwujudnya hidup bersih dan sehat.
Penelitian ini sebanding dengan penelitian yang dilakukan oleh (Iswara et al., 2013) tentang Pembelajaran "Calistung" pada anak-anak usia dini di TK Sekolah Alam Bandung dengan metode bernyanyi sehingga bisa meningkatkan pengetahuan tanpa merasa ada paksaan, sehingga siswa/i dapat selalu merasa riang gembira serta mudah untuk mengingat materi yang diberikan.

Tabel 1. Karakteristik Responden di SD Negeri 154 Desa Teluk Jambu

\begin{tabular}{lcc}
\hline $\begin{array}{c}\text { Jenis } \\
\text { Kelamin }\end{array}$ & Jumlah & $\begin{array}{c}\text { Persentase } \\
(\mathbf{\%})\end{array}$ \\
\hline Perempuan & 34 & 42 \\
\hline Laki-Laki & 47 & 58 \\
\hline Total & 81 & 100 \\
\hline
\end{tabular}

Adanya pengaruh jenis kelamin terhadap tahapan cuci tangan yang benar (Susantiningsih, 2018). Antara laki-laki dan perempuan memiliki perbedaan kebiasaan pola hidup bersih. Hal tersebut dapat menyebabkan perilaku cuci tangan antara lakilaki dan perempuan dapat berbeda. Perlunya pembelajaran yang lebih terhadap siswa laki - laki supaya dapat menjadi pengaruh besar untuk siswi permpuan melakukan hal yang serupa, yait mencuci tangan pakai sabun. Agar tercapainya target penelitian ini supaya perilaku siswa/i dapat berubah setelah diberikan pembelajaran mengenai cuci tangan pakai sabun, baik itu bahaya jika tidak mencuci tangan maupun keuntungan jika rajin mencuci tangan.

\section{SIMPULAN}

Dapat disimpulkan bahwa setelah pemberian intervensi Cara Cuci Tangan $\mathrm{Pa}-$ kai Sabun siswa/I SD Negeri 154 Desa Teluk Jambu Muaro Jambi lebih memahami cara pola hidup bersih dan sehat dengan selalu menjaga kebersihan dan selalu mencuci tangan dengan menggunakan sabun sebelum beraktifitas dan setelah beraktivitas 
Available online at https://jurnal.stmikroyal.ac.id/index.php/jurdimas

\section{UCAPAN TERIMA KASIH}

Kami mengucapakan terima kasih yang sebesar - besarnya kepada Kepala Sekolah SDN 154 Desa Teluk Jambu Muaro Jambi serta para siswa/i yang sangat antusias dan bersemangat dengan kegiatan yang kami laksanakan.

\section{DAFTAR PUSTAKA}

Al-Gallas, N., Bahri, O., Bouratbeen, A., Haasen, A. Ben, \& Aissa, R. Ben. (2007). Etiology of acute diarrhea in children and adults in Tunis, Tunisia, with emphasis on diarrheagenic Escherichia coli: Prevalence, phenotyping, and molecular epidemiology. American Journal of Tropical Medicine and Hygiene, 77(3), 571-582. https://doi.org/10.4269/ajt

mh.2007.77.571

Andriansyah, Y., \& Rahmantari, D. N. (2013). Penyuluhan Dan Praktik Phbs ( Perilaku Hidup Bersih. Inovasi Dan Kewirausahaan, 2(1), 45-50.

Bangun, H. A. (2020). Sosialisasi Cuci Tangan Pakai Sabun Di PAUD dan Taman Kanak - Kanak Sekolah Sinar Mentari Desa Percut Sei Tuan Kabupaten Deli Serdang Sumatera Utara. 1, 59-68.

Chang, J. Y., Antonopoulos, D. A., Kalra, A., Tonelli, A., Khalife, W. T., Schmidt, T. M., \& Young, V. B. (2008). Decreased Diversity of the Fecal Microbiome in Recurrent Clostridium difficile Associated Diarrhea . The Journal of Infectious Diseases, 197(3), 435-438. https://doi.org/10.1086/525047

Cordita, R. N. (2017). Perbandingan Efektifitas Mencuci Tangan Menggunaakan Hand Sanitizier dengan sabun antiseptik pada tenaga kesehatan di ICU RSUD Dr. H Abdul Aoeloek. The Chemical, 53(9), 1689-1699. https://doi.org/10.1017/CBO978110741 5324.004

Desiyanto, F. A., \& Djannah, S. N. (2013).
Efektivitas Mencuci Tangan Menggunakan Cairan Pembersih Tangan Antiseptik (Hand Sanitizer) Terhadap Jumlah Angka Kuman. Jurnal Kesehatan Masyarakat (Journal of Public Health), 7(2), 75-82. https://doi.org/10.12928/kesmas.v7i2.1 041

IDAI. (2012). Buku Ajar GastroenterologiHepatologi. Badan Penerbit Ikatan Dokter Anak Indonesia.

Iswara, P. P., Latifah, D., \& Budiwati, D. S. (2013). Studi Tentang Kegiatan Bernyanyi Pada Pembelajaran ??Calistung? Untuk Anak Usia Dini Di Tk Sekolah Alam Bandung. Swara: Jurnal Antologi Departemen Pendidikan Seni Musik FPSD UPI, 1(3).

Lailatul Mafazah. (2013). Ketersediaan Sarana Sanitasi Dasar, Personal Hygiene Ibu Dan Kejadian Diare. Kemas - Jurnal Kesehatan Masyarakat, 8(2), $\quad$ 176-182. https://doi.org/10.15294/kemas.v8i2.28 19

Organization, W. H. (2009). Langkah Mencuci Tangan Yang Benar.

Ri, D. K. (2009). Panduan Penyelenggaraan Cuci Tangan Pakai Sabun Sedunia (HCTPS). Jakarta.

Simatupang, R., \& Simatupang, M. (2019). Pengaruh Pendidikan Kesehatan Terhadap Perilaku Cuci Tangan Pakai Sabun Dengan Air Mengalir Anak Sd Di Sekolah Dasar Negeri 157019 Pinangsori 12 Kabupaten Tapanuli Tengah Tahun 2018. Jurnal Keperawatan Dan Fisioterapi (Jkf), 2(1), 67-73. https://doi.org/10.35451/jkf.v2i1.295

Susantiningsih, T., Yuliyanti, R., Simanjuntak, K., \& Arfiyanti. (2018). PKM Pelatihan Memcuci Tangan Menggunakan Sabun Sebagai Perilaku Hidup Bersih Dan Sehat Untuk Masyarakat RT 007/RW 007 Desa Pangkalan Jati, Kecamatan Cinere Kota Depok. Bakti Masyarakat Indonesia, 1(2), 75-84. 
Jurdimas (Jurnal Pengabdian Kepada Masyarakat) Royal

Vol. 3 No. 2, Juli 2020, hlm 93 - 98.

DOI: https://doi.org/10.33330/jurdimas.v3i2.589

ISSN 2622-3813 (Online)

Available online at https://jurnal.stmikroyal.ac.id/index.php/jurdimas

Umaroh, A. K., Hanggara, H. Y., \& Choiri, C. (2016). Gambaran Perilaku Hidup Bersih Dan Sehat (Phbs) Di Wilayah Kerja Puskesmas Bulu Kabupaten Sukoharjo Bulan Januari-Maret 2015. Jurnal Kesehatan, 9(1), 25. https://doi.org/10.23917/jurkes.v9i1.33 75
Utami, N. F. (2018). Perilaku cuci tangan pakai sabun dengan stategi pemberdayaan guru melalui tahap adaptasi, inovasi, dan mandiri pada siswa kelas iv di sdit al qalam kota kendari tahun 2017. 3(1), 1-10. 